OPEN ACCESS

Edited by: Pietro Celi,

DSM Nutritional Products, USA

Reviewed by:

Barry Bradford,

Kansas State University, USA

Gerald Huntington,

North Carolina State University, USA

*Correspondence:

James L. Klotz

james.klotz@ars.usda.gov

Specialty section:

This article was submitted to Animal Nutrition and Metabolism,

a section of the journal

Frontiers in Nutrition

Received: 11 August 2015 Accepted: 05 October 2015 Published: 19 October 2015

Citation:

Jia Y, Harmon DL, Flythe MD and

Klotz JL (2015) Interaction of isoflavones and endophyte-infected

tall fescue seed extract on

vasoactivity of bovine mesenteric vasculature.

Front. Nutr. 2:32

doi: 10.3389/fnut.2015.00032

\section{Interaction of isoflavones and endophyte-infected tall fescue seed extract on vasoactivity of bovine mesenteric vasculature}

\author{
Yang Jia ${ }^{1}$, David L. Harmon ${ }^{1}$, Michael D. Flythe ${ }^{2}$ and James L. Klotz ${ }^{2 *}$ \\ ${ }^{1}$ Department of Animal and Food Sciences, University of Kentucky, Lexington, KY, USA, ${ }^{2}$ Forage-Animal Production \\ Research Unit, Agricultural Research Service, United States Department of Agriculture, Lexington, KY, USA
}

It was hypothesized that isoflavones may attenuate ergot alkaloid-induced vasoconstriction and possibly alleviate diminished contractility of vasculature after exposure to ergot alkaloids. The objective of this study was to determine if prior incubation of bovine mesenteric vasculature with the isoflavones formononetin $(F)$, biochanin $A(B)$, or an ergovaline-containing tall fescue seed extract (EXT) and their combinations affect ergotamine (ERT)-induced contractility. Multiple segments of mesenteric artery and vein supporting the ileal flange of the small intestine were collected from Angus heifers at slaughter $(n=5$, bodyweight $=639 \pm 39 \mathrm{~kg}$ ). Duplicates of each vessel type were incubated in tissue culture flasks at $37^{\circ} \mathrm{C}$ with a 50-mL volume of Krebs-Henseleit buffer containing: only buffer (control); or $1 \times 10^{-6} \mathrm{M} \mathrm{EXT;} \mathrm{F;} \mathrm{or} B$; and combinations of $1 \times 10^{-6} \mathrm{M} \mathrm{EXT}+F ; 1 \times 10^{-6} \mathrm{M}$ $\mathrm{EXT}+B ; 1 \times 10^{-6} \mathrm{MF}+B$; or $1 \times 10^{-6} \mathrm{M} \mathrm{EXT}+F+B$. After incubation for $2 \mathrm{~h}$, sections were mounted in a multimyograph chamber. The ERT dose responses were normalized to $0.12 \mathrm{M} \mathrm{KCl}$. Pretreatment with $F, B$, and $F+B$ without EXT resulted in similar contractile responses to ERT in mesenteric artery and all incubations containing EXT resulted in a complete loss of vasoactivity to ERT. In mesenteric artery pretreated with EXT, treatments that contained $B$ had higher contractile responses $(P<0.05)$ at ERT concentrations of $1 \times 10^{-7}$ and $5 \times 10^{-7} \mathrm{M}$. Also, treatments containing $B$ tended $(P<0.1)$ to have greater responses than treatments without $B$ at ERT concentrations of $1 \times 10^{-6}, 5 \times 10^{-6}$, and $5 \times 10^{-5} \mathrm{M}$. In mesenteric vein pretreated with EXT, treatments containing $F$ had greater contractile responses to ERT at $1 \times 10^{-5}, 5 \times 10^{-5}$, and $1 \times 10^{-4} \mathrm{M}(P<0.05)$. These data indicated that $F$ and $B$ at $1 \times 10^{-6} \mathrm{M}$ and their combination did not impact the overall contractile response to ERT in mesenteric vasculature. However, $F$ and $B$ may offset some of the vasoconstriction caused by prior exposure to ergot alkaloids.

Keywords: ergot alkaloids, isoflavones, mesenteric vasculature, vasoconstriction

\section{INTRODUCTION}

As a symbiotic endophyte of tall fescue (Lolium arundinaceum) (1-4), Epichloë coenophiala produces a variety of ergot alkaloids $(5,6)$, which have been identified as causative agents of vasoconstriction and symptoms of fescue toxicosis in grazing animals $(7,8)$. Ergovaline and ergotamine commonly draw more attention of researchers. Lyons et al. (5) reported that ergovaline 
was the predominant (84-97\%) alkaloid of all the five detected ergopeptine alkaloids from tall fescue (Lolium arundinaceum) pasture. Numerous studies have reported that ergot alkaloids (ergovaline and ergotamine) induce vasoconstriction in peripheral blood vessel models such as the caudal artery (9, 10), dorsal pedal vein (11), and lateral saphenous vein (12), and also core blood vessel models like the right ruminal artery and vein (13), bovine uterine and umbilical arteries (14), and mesenteric artery and vein (15). Consistent with findings in the bovine lateral saphenous vein $(16,17)$, Egert et al. (15) demonstrated that previous dietary exposure to ergot alkaloids reduced the vasoactivity in bovine mesenteric vasculature.

Isoflavones are almost exclusively found in the legume (Leguminosae/Fabaceae) family, such as soybean, chickpeas, and red clover $(18,19)$. A variety of isoflavones, such as genistein, daidzein, biochanin A $(B)$, and formononetin $(F)$, have been shown to elicit different beneficial effects on humans in many different ways, for example, improvements to the cardiovascular system, osteoporosis, anti-breast, and prostate cancer (20-23). Substantial evidence has been published on the vasodilative effects of isoflavones and their metabolites in different vessel types in humans $(24,25)$ and rats $(26-29)$. However, based on our knowledge, no studies have investigated the vasodilative effects of isoflavones on bovine vessels.

Ergot alkaloids share some structural similarities with biogenic amines (i.e., dopamine, epinephrine, norepinephrine, serotonin) and thus can cause vasoconstriction by binding biogenic amine receptors (30) found throughout the body. On the other hand, isoflavones have estrogenic activities and could cause endothelium-dependent or -independent vasorelaxation. Although the precise mechanisms behind the vascular bioactivity of both ergot alkaloids and isoflavones have not been fully defined, current knowledge suggests that they are triggered by different mechanisms. Nevala et al. (31) reported that isoflavones relax noradrenaline precontracted rat mesenteric arteries. Likewise, Egert et al. (15) demonstrated that ergot alkaloids were vasoconstrictive in bovine mesenteric vasculature, whereas dietary exposure to ergot alkaloids decreased the contractility of mesenteric vasculature. Thus, it was hypothesized that isoflavones may attenuate ergot alkaloid-induced vasoconstriction and possibly alleviate the diminished contractility of mesenteric vasculature after preliminary exposure to ergot alkaloids. The objective of this study was to determine if an incubation of bovine mesenteric vasculature with $F, B$, or ergovaline-containing tall fescue seed extract (EXT) and their combinations affect ergotamine (ERT)induced contractility.

\section{MATERIALS AND METHODS}

No live animals were involved this study, so approval from the University of Kentucky Animal Care and Use Committee was not required.

\section{Animals and Tissue Collection}

Five Angus heifers (Bodyweight $=639 \pm 39 \mathrm{~kg}$ ) were slaughtered and tissues were collected at the University of Kentucky abattoir. As originally described by Klotz and Barnes (32), the gastrointestinal tract was removed from the carcass, and the cecum, ileocecal fold, and the ileal flange were identified as landmarks. Within the mesentery supporting the ileal flange, multiple branches of the mesenteric artery and vein bundles were dissected and submerged in oxygenated Krebs-Henseleit buffer $\left(95 \% \mathrm{O}_{2} / 5 \% \mathrm{CO}_{2} ; \mathrm{pH}=7.4 ; 11.1 \mathrm{mM}\right.$ D-glucose; $1.2 \mathrm{mM}$ $\mathrm{MgSO}_{4} ; 1.2 \mathrm{mM} \mathrm{KH}_{2} \mathrm{PO}_{4} ; 4.7 \mathrm{mM} \mathrm{KCl} ; 118.1 \mathrm{mM} \mathrm{NaCl} ; 3.4 \mathrm{mM}$ $\mathrm{CaCl}_{2} ; 24.9 \mathrm{mM} \mathrm{NaHCO}$; Sigma Chemical Co., St. Louis, MO, USA) for transport to the laboratory. Samples were stored on ice until cleaned. At the time of cleaning, surrounding fat and connective tissues were carefully removed, and mesentery artery and vein were separated under a magnifying lamp (2.5 to $5.0 \times$ magnification). Cleaned vessels were sliced into 2 - $\mathrm{mm}$ segments and examined under a dissecting scope (Semi 2000-C, Carl Zeiss Inc., Oberkochen, Germany) at $12.5 \times$ magnification to ensure the usability of the vessels. Cross-sections with abnormalities (branches, valves, or structural damage) were replaced with structurally integral ones.

\section{Pre-Myograph Incubations}

A tall fescue seed extract was prepared as described by Foote et al. (33) to contain a $1 \times 10^{-6} \mathrm{M}$ working concentration of ergovaline. Duplicates of each vessel type (from each animal) were incubated in tissue culture flasks with a 50-mL volume of Krebs-Henseleit buffer containing: only buffer (control); $1 \times 10^{-6} \mathrm{M}$ EXT; $1 \times 10^{-6}$ M F ( $\geq 99.0 \%$; 47752-5MG-F; Sigma Chemical Co., St. Louis, MO, USA); or $1 \times 10^{-6} \mathrm{M} B$ (D2016; Sigma Chemical Co., St. Louis, MO, USA); and combinations of $1 \times 10^{-6} \mathrm{M} \mathrm{EXT}+F$; $1 \times 10^{-6} \mathrm{M} \mathrm{EXT}+B ; 1 \times 10^{-6} \mathrm{M} F+B ;$ or $1 \times 10^{-6} \mathrm{M} \mathrm{EXT}+F+B$. All buffer solutions were prewarmed for $30 \mathrm{~min}$ in a $\mathrm{CO}_{2}$ incubator $\left(95 \% \mathrm{O}_{2} / 5 \% \mathrm{CO}_{2} ; 37^{\circ} \mathrm{C}\right.$; Nu-8500, NUAIRE, Inc., Plymouth, MN, USA) prior to blood vessel addition. Duplicate blood vessel segments were randomly placed into each treatment flask and incubated in the same conditions for $2 \mathrm{~h}$. Immediately after the 2-h incubation, dimensional measurements of cross-sections were recorded only for mesentery artery using Axiovision (version 20, Carl Zeiss, Inc.).

\section{Experimental Myograph Protocol}

Following the 2-h incubations, an ERT concentration response experiment was conducted using the procedures described by Klotz and Barnes (32). ERT (ergotamine D-tartrate; 97\%; 45510; Aldrich, Milwaukee, WI, USA) standards were prepared by diluting a stock solution $(0.0201 \mathrm{M})$ with dimethyl sulfoxide to working concentrations that resulted in a concentration range of $5 \times 10^{-9}$ to $1 \times 10^{-4} \mathrm{M}$ in the myograph chamber (contained $5 \mathrm{~mL}$ of Krebs-Henseleit buffer).

Artery and vein cross-sections were mounted on the myograph (Multichamber myograph; DMT 610M, Danish Myo Technology, Atlanta, GA, USA) by inserting the supports through the lumen in individual myograph chambers containing $5 \mathrm{~mL}$ modified Krebs-Henseleit buffer and continuously gassed (95\% $\mathrm{O}_{2} / 5 \% \mathrm{CO}_{2} ; \mathrm{pH}=7.4 ; 37^{\circ} \mathrm{C}$ ). The incubation buffer was modified from transport Krebs-Henseleit buffer by adding desipramine $\left(3 \times 10^{-5} \mathrm{M}\right.$; D3900; Sigma Chemical Co.) to inhibit the reuptake mechanisms of biogenic amines and propranolol $\left(1 \times 10^{-6} \mathrm{M}\right.$; P0844; Sigma Chemical Co.) to block the non-specific binding 
of ERT to $\beta$-adrenergic receptors. A 90 -min equilibration period with buffer replacement occurring every 15 min was completed based on the conditions above to achieve a stable resting tension of approximately $1 \mathrm{~g}$. Following the equilibration period, the blood vessels were exposed to $120 \mathrm{mM} \mathrm{KCl}$ for $15 \mathrm{~min}$ to evaluate tissue viability and to normalize treatment data. Following the $\mathrm{KCl}$ addition, the incubation buffer was replaced every $15 \mathrm{~min}$ until vessel tension returned to the $1 \mathrm{~g}$ baseline. Once the vessel returned to baseline, addition of ERT standards was initiated in order to increase the concentration. ERT additions were added in 15-min intervals consisting of a 9-min-incubation period, two 2.5-min buffer washes, and a third, final buffer replacement that was followed by 1-min recovery before the next ERT addition. This 15 min cycle was repeated for the rest of the nine remaining ERT additions. Following the 1-min recovery after the final ERT addition, vessels were again exposed to $120 \mathrm{mM} \mathrm{KCl}$ to confirm the vessel viability at the end of the experiment.

\section{Data Collection}

The isometric contractions of the different preincubated mesenteric vessels to $\mathrm{KCl}$ and ERT additions were digitized and recorded as grams of tension using a PowerLab/8sp and Chart software (version 7.3, ADInstruments, Colorado Springs, Co.). Baseline tension was measured immediately before the addition of $120 \mathrm{mM} \mathrm{KCl}$. For all contractile response data, the maximum observed tension (in grams) in the 9 min-incubation period was recorded as the contractile response. Contractile response data were corrected for baseline tension and normalized as a percentage of the reference compound $\mathrm{KCl}$ induced maximum contractile response. The differences of tissue response due to the variations of vessel size and across individual animal were minimized by this data normalization. The contractile response to ERT was determined and presented as percentage means \pm SEM. A measurement of potency or the half-maximal effective concentration $\left(\mathrm{EC}_{50}\right)$ was calculated using GraphPad Prism (version 5; GraphPad Software Inc., La Jolla, CA, USA) using a non-linear regression with fixed slope. The sigmoidal concentration response curves of pretreated mesentery artery and vein to ERT was plotted by using a three-parameter equation:

$$
y=\text { bottom }+\left(\frac{\text { top-bottom }}{\left[1+10^{\left(\log \mathrm{EC}_{50}-x\right)}\right]}\right),
$$

where $y$ represents contractile response, and $x$ denotes the agonist concentration, top and bottom are the plateaus of contractile response as percentage of $120 \mathrm{mM} \mathrm{KCl}$ maximum response. The $\mathrm{EC}_{50}$ is the molar concentration of ERT inducing $50 \%$ of the $\mathrm{KCl}$ maximum response.

\section{Statistics}

All data were analyzed using the MIXED model of SAS (SAS 9.4, SAS Inst. Inc., Cary, NC, USA). Contractile response data of mesentery artery and vein were analyzed separately as two datasets for treatments with and without EXT. Data for contractile response (within each ERT concentration), $\mathrm{KCl}$ maximal response, inside and outside diameters for mesenteric artery (these data could not be obtained for mesenteric vein samples due to the pliable nature of this vessel) were analyzed as a completely randomized design with a factorial treatment arrangement. The fixed effects included the effects of $F, B$, and the interaction of $F \times B$ in the presence or absence of EXT. Due to the shape of the response curve, $\mathrm{EC}_{50}$ data were analyzed only in treatments without EXT from mesentery artery using a completely randomized design with treatment as fixed variable. For all data, pair-wise comparisons of least square means $( \pm$ SEM) were only performed if the probability of a greater $F$-statistic from the analysis of variance was significant for the tested effect and interaction. Mean separation was performed with the LSD feature of SAS. Differences are denoted as significant at $P<0.05$, unless specifically reported otherwise.

\section{RESULTS}

The $F$ and $B$ incubation pretreatment did not impact $(P>0.05)$ the maximum contractile response of mesenteric artery or mesenteric vein to $120 \mathrm{mM} \mathrm{KCl}$ either without EXT (Table 1) or with EXT (Table 2). The pretreatments with EXT did not compromise the vessel viability, which was indicated by the ending response to $\mathrm{KCl}$ for either the artery or vein (Figure 1). In mesenteric artery, the inside and outside diameters after the $2 \mathrm{~h}$ incubation were not affected $(P>0.05)$ by $F$ or $B$ in both treatment groups with (Table 2) or without EXT (Table 1). However, there was a tendency $(P=0.07)$ for $F$ treated vessels to have a larger inside diameter for those pretreated with EXT (Table 2), and a smaller outside diameter $(P=0.09)$ for those not pretreated with EXT (Table 1). Interestingly, mesenteric artery pretreated with $B$ tended $(P=0.06)$ to have a smaller inside diameter when incubated with EXT (Table 2).

In the mesenteric artery, ERT induced similar contractile responses in all treatments (Figure 2) with $-\log ^{\mathrm{EC} 50}$ values $(5.99 \pm 0.14,5.80 \pm 0.14,5.88 \pm 0.14,5.74 \pm 0.14 \mathrm{M}$, respectively) that did not differ with each other $(P=0.63)$. Within each ERT concentration, tendencies for $F \times B$ interactions in mesenteric artery were observed at ERT $5 \times 10^{-9}, 1 \times 10^{-8}$, $5 \times 10^{-8} \mathrm{M}(P=0.09, P=0.07, P=0.08$, respectively; Table 3$)$ for treatments without EXT. Contractile responses of $F+B$ treated mesentery artery were greater than $B$ at ERT concentrations $1 \times 10^{-8}$ and $5 \times 10^{-8} \mathrm{M}(P<0.05)$. In mesenteric vein, ERTinduced contractile responses reached the maximum response at $1 \times 10^{-6} \mathrm{M}$ for Control, $B, F, F+B$ treatments (Figure 3), and then relaxed to negative response values with increases in ERT concentration.

For the blood vessels incubated with EXT, the contractile responses decreased as the concentration of ERT increased in both mesenteric artery (Figure 4) and mesenteric vein (Figure 5). In mesenteric artery, a main effect of $B$ was observed at ERT concentrations of $1 \times 10^{-7}$ and $5 \times 10^{-7} \mathrm{M}$ (Table 4), with treatments that contained $B$ having higher contractile responses $(P<0.05)$. Also, treatments containing $B$ tended $(P<0.1)$ to have greater responses than treatments without $B$ at ERT concentrations of $1 \times 10^{-6}, 5 \times 10^{-6}$, and $5 \times 10^{-5} \mathrm{M}$ (Table 4).

In the mesenteric vein, the contractile response of all treatments with EXT to ERT decreased and remained below zero from the second ERT addition $\left(1 \times 10^{-8} \mathrm{M}\right)$ to the last addition at 
TABLE 1 | Inside diameter, outside diameter, and SEM of mesenteric artery, and the mean $\mathrm{KCI}$ maximum response of mesenteric artery and vein to pretreatment without tall fescue extract: only Krebs-Henseleit buffer (control); $1 \times 10^{-6} \mathrm{M}$ treatments of formononetin $(F)$, biochanin $A(B)$, and combination of $F$ and $B(F+B)$.

\begin{tabular}{|c|c|c|c|c|c|c|c|c|}
\hline \multirow[t]{2}{*}{ Item } & \multirow[t]{2}{*}{ Control } & \multirow[t]{2}{*}{$F$} & \multirow[t]{2}{*}{$B$} & \multirow[t]{2}{*}{$F+B$} & \multirow[t]{2}{*}{ SEM } & \multicolumn{3}{|c|}{$P$-value } \\
\hline & & & & & & $\boldsymbol{F}$ & $B$ & $F \times B$ \\
\hline \multicolumn{9}{|l|}{ Mesenteric artery } \\
\hline $\mathrm{KCl}$ maximum response $(\mathrm{g})$ & 4.36 & 4.42 & 4.22 & 3.66 & 0.46 & 0.58 & 0.33 & 0.50 \\
\hline Inside diameter (mm) & 0.81 & 0.79 & 0.86 & 0.77 & 0.06 & 0.38 & 0.77 & 0.61 \\
\hline Outside diameter (mm) & 1.72 & 1.64 & 1.75 & 1.57 & 0.07 & 0.09 & 0.74 & 0.47 \\
\hline \multicolumn{9}{|l|}{ Mesenteric vein ${ }^{a}$} \\
\hline $\mathrm{KCl}$ maximum response (g) & 1.70 & 1.81 & 1.89 & 2.22 & 0.21 & 0.31 & 0.18 & 0.62 \\
\hline
\end{tabular}

${ }^{a}$ Due to the elasticity of the mesenteric vein, measurements of vascular dimensions were not possible.

TABLE 2 | Inside diameter, outside diameter, and SEM of mesenteric artery, and the mean $\mathrm{KCI}$ maximum response of mesenteric artery and vein to pretreatment with tall fescue seed extract: $1 \times 10^{-6} \mathrm{M}$ ergovaline-containing tall fescue seed extract (EXT); combinations of $1 \times 10^{-6} \mathrm{M}$ EXT and formononetin $(F)$, EXT and biochanin $A(B)$, and the combination of EXT $+F+B$.

\begin{tabular}{|c|c|c|c|c|c|c|c|c|}
\hline \multirow[t]{2}{*}{ Item } & \multirow[t]{2}{*}{ EXT } & \multirow[t]{2}{*}{$E X T+F$} & \multirow[t]{2}{*}{$E X T+B$} & \multirow[t]{2}{*}{$\mathrm{EXT}+F+B$} & \multirow[t]{2}{*}{ SEM } & \multicolumn{3}{|c|}{$P$-value } \\
\hline & & & & & & $\boldsymbol{F}$ & $B$ & $F \times B$ \\
\hline \multicolumn{9}{|l|}{ Mesenteric artery } \\
\hline $\mathrm{KCl}$ maximum response $(\mathrm{g})$ & 3.43 & 2.68 & 3.08 & 2.84 & 0.37 & 0.19 & 0.80 & 0.50 \\
\hline Inside diameter (mm) & 0.72 & 0.78 & 0.60 & 0.72 & 0.05 & 0.07 & 0.06 & 0.50 \\
\hline Outside diameter (mm) & 1.64 & 1.57 & 1.51 & 1.59 & 0.07 & 0.92 & 0.43 & 0.29 \\
\hline \multicolumn{9}{|l|}{ Mesenteric vein ${ }^{a}$} \\
\hline $\mathrm{KCl}$ maximum response $(\mathrm{g})$ & 1.90 & 2.20 & 2.09 & 2.49 & 0.21 & 0.11 & 0.26 & 0.81 \\
\hline
\end{tabular}

${ }^{a}$ Due to the elasticity of the mesenteric vein, measurements of vascular dimensions were not possible.

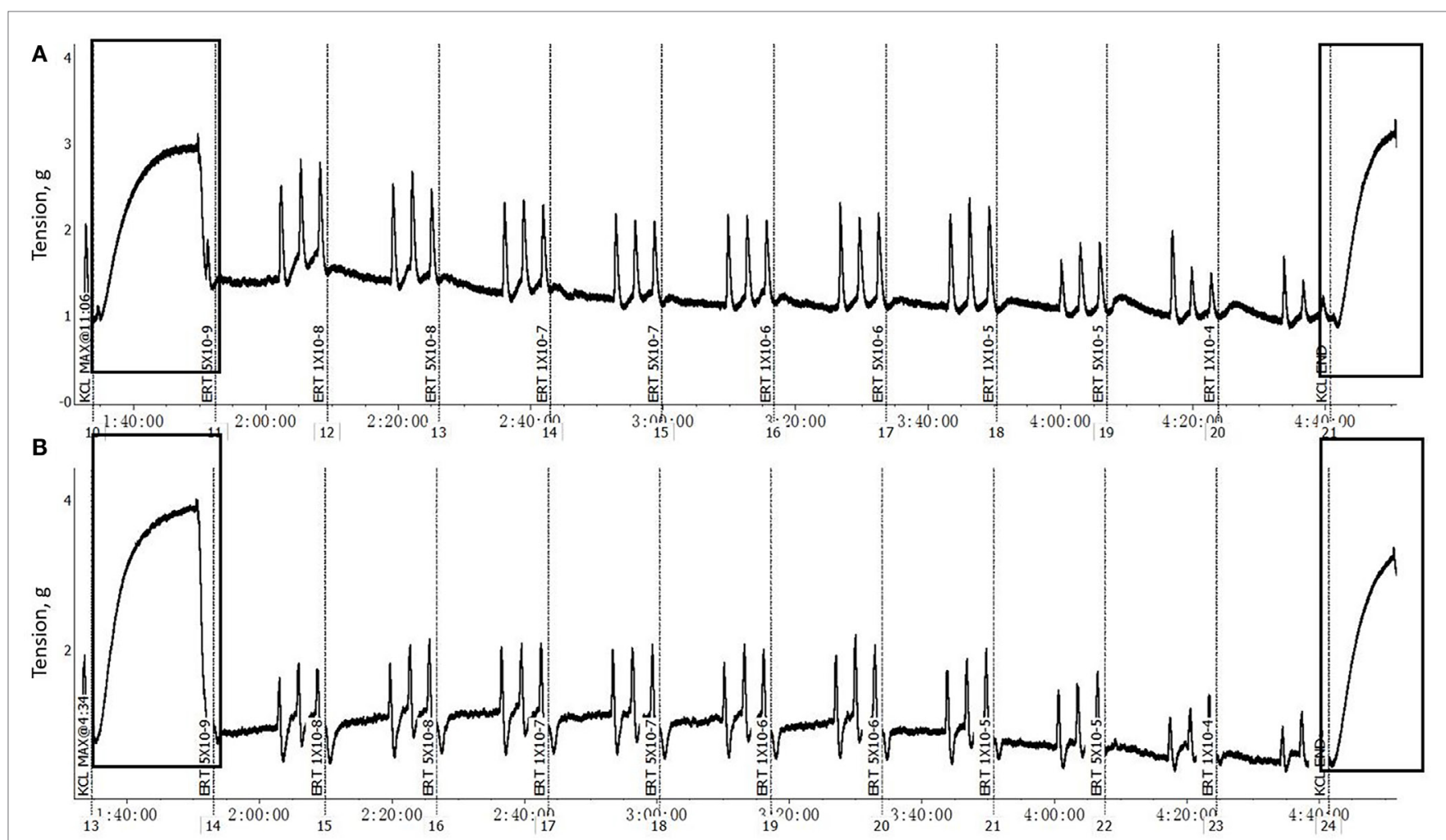

FIGURE 1 | Example of a typical response of mesenteric artery (A) and vein $(B)$ cross-sections, after pretreated with $1 \times 10^{-6} M$ EXT and $1 \times 10^{-6} M^{F}$ and $\mathbf{1} \times \mathbf{1 0 ^ { - 6 }} \mathbf{M} \mathbf{B}(\mathbf{E X T}+\boldsymbol{F}+\boldsymbol{B})$, to increasing concentrations of ERT $\left(\mathbf{5} \times \mathbf{1 0}^{-9}\right.$ to $\left.\mathbf{1} \times \mathbf{1 0 ^ { - 4 }} \mathbf{M}\right)$. The rectangles highlighted regions are the initial and end $\mathrm{KCl}$ (0.12 M) additions. 


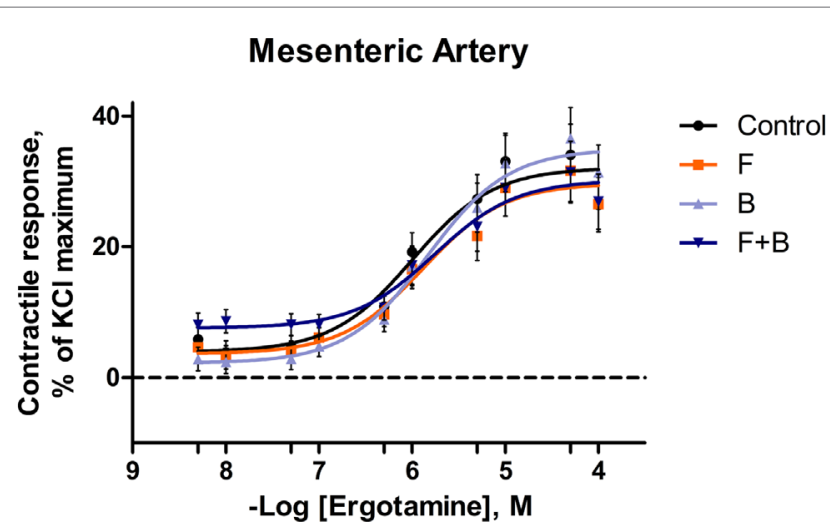

FIGURE 2 | Mean contractile response, as \% $\mathrm{KCl}$ maximum of mesenteric artery to increasing concentrations of ergotamine for pretreatments without tall fescue seed extract: only Krebs-Henseleit buffer (control); $1 \times 10^{-6} \mathrm{M}$ formononetin $(F)$; or $1 \times 10^{-6} \mathrm{M}$ biochanin $\mathrm{A}$ $(B)$; and combination of $1 \times 10^{-6} \mathbf{M} F$ and $1 \times 10^{-6} \mathbf{M} B(F+B)$. The regression lines were plotted for each treatment using a non-linear regression with fixed slope, and the sigmoidal concentration response curves were calculated by the following equation: $y=$ bottom $+\left[(\right.$ top-bottom $\left.) /\left(1+10^{\left(\operatorname{logEC}_{50}-x\right)}\right)\right]$ where top and bottom are the plateaus of contractile response as percentage of $120 \mathrm{mM} \mathrm{KCl}$ maximum response. $\mathrm{EC}_{50}$ is the molar concentration of ergotamine inducing $50 \%$ of the $\mathrm{KCl}$ maximum response.

TABLE 3 | The analysis of variance and $P$-values of main effect of formononetin $(F)$, biochanin $A(B)$, and the interaction of formononetin and biochanin $A(F \times B)$ for pretreatments without tall fescue extract: only Krebs-Henseleit buffer; $1 \times 10^{-6} M F, B$, and combination of $F$ and $B$ on every ergotamine concentration.

\begin{tabular}{|c|c|c|c|}
\hline \multirow[t]{2}{*}{ Ergotamine concentration (M) } & \multicolumn{3}{|c|}{$P$-value } \\
\hline & $\boldsymbol{F}$ & $B$ & $F \times B$ \\
\hline \multicolumn{4}{|l|}{ Mesenteric artery } \\
\hline $5 \times 10^{-9}$ & 0.23 & 0.91 & 0.09 \\
\hline $1 \times 10^{-8}$ & 0.14 & 0.27 & 0.07 \\
\hline $5 \times 10^{-8}$ & 0.20 & 0.51 & 0.08 \\
\hline $1 \times 10^{-7}$ & 0.29 & 0.83 & 0.31 \\
\hline $5 \times 10^{-7}$ & 0.88 & 0.79 & 0.43 \\
\hline $1 \times 10^{-6}$ & 0.68 & 0.78 & 0.64 \\
\hline $5 \times 10^{-6}$ & 0.27 & 0.99 & 0.72 \\
\hline $1 \times 10^{-5}$ & 0.38 & 0.97 & 0.97 \\
\hline $5 \times 10^{-5}$ & 0.43 & 0.81 & 0.77 \\
\hline $1 \times 10^{-4}$ & 0.61 & 0.54 & 0.59 \\
\hline \multicolumn{4}{|l|}{ Mesenteric vein } \\
\hline $5 \times 10^{-9}$ & 0.92 & 0.27 & 0.85 \\
\hline $1 \times 10^{-8}$ & 1.00 & 0.96 & 0.50 \\
\hline $5 \times 10^{-8}$ & 0.67 & 0.67 & 0.28 \\
\hline $1 \times 10^{-7}$ & 0.80 & 0.64 & 0.41 \\
\hline $5 \times 10^{-7}$ & 0.99 & 0.43 & 0.74 \\
\hline $1 \times 10^{-6}$ & 0.93 & 0.30 & 0.70 \\
\hline $5 \times 10^{-6}$ & 0.78 & 0.43 & 0.70 \\
\hline $1 \times 10^{-5}$ & 0.50 & 0.80 & 0.62 \\
\hline $5 \times 10^{-5}$ & 0.29 & 0.93 & 0.61 \\
\hline $1 \times 10^{-4}$ & 0.23 & 0.86 & 0.89 \\
\hline
\end{tabular}

$1 \times 10^{-4} \mathrm{M}$. Tendencies for main effects of $B(P=0.06)$ and $F \times B$ interaction $(P=0.09)$ were observed at ERT concentrations of $5 \times 10^{-9} \mathrm{M}$, where EXT treatment had a lower contractile response than $\mathrm{EXT}+B(P<0.05$; Table 4$)$. Treatments containing $F$ had

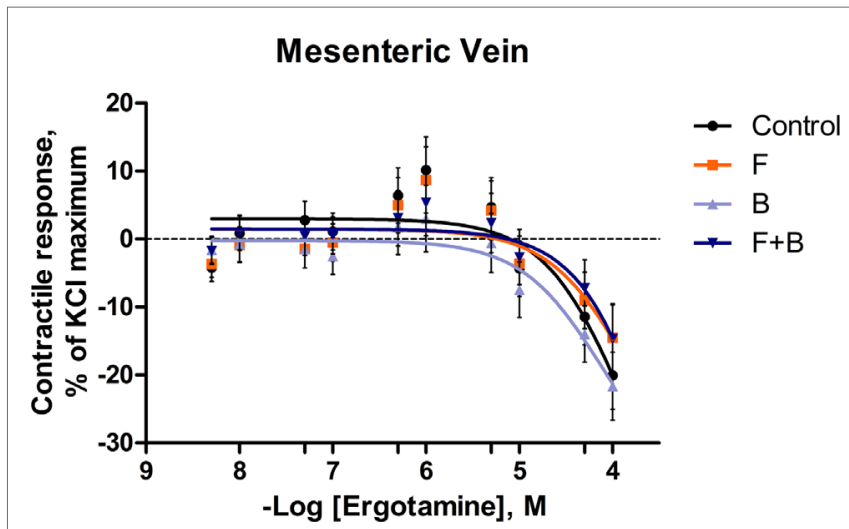

FIGURE 3 | Mean contractile response, as \% $\mathrm{KCl}$ maximum of mesenteric vein to increasing concentrations of ergotamine for pretreatments without tall fescue seed extract: only KrebsHenseleit buffer (control); $1 \times 10^{-6} \mathrm{M}$ formononetin $(F)$; or $1 \times 10^{-6} \mathrm{M}$ biochanin $\mathrm{A}(B)$; and combination of $1 \times 10^{-6} \mathrm{M} F$ and $\mathbf{1} \times \mathbf{1 0}^{-\mathbf{6}} \mathbf{M} \boldsymbol{B}(\boldsymbol{F}+\boldsymbol{B})$. The regression lines were plotted for each treatment using a non-linear regression with fixed slope, and the sigmoidal concentration response curves were calculated by the following equation: $y=$ bottom $+\left[(\right.$ top-bottom $\left.) /\left(1+10^{\left(\log _{E C_{50}}-\mathrm{x}\right)}\right)\right]$ where top and bottom are the plateaus of contractile response as percentage of $120 \mathrm{mM} \mathrm{KCl}$ maximum response. $\mathrm{EC}_{50}$ is the molar concentration of ergotamine inducing $50 \%$ of the $\mathrm{KCl}$ maximum response.

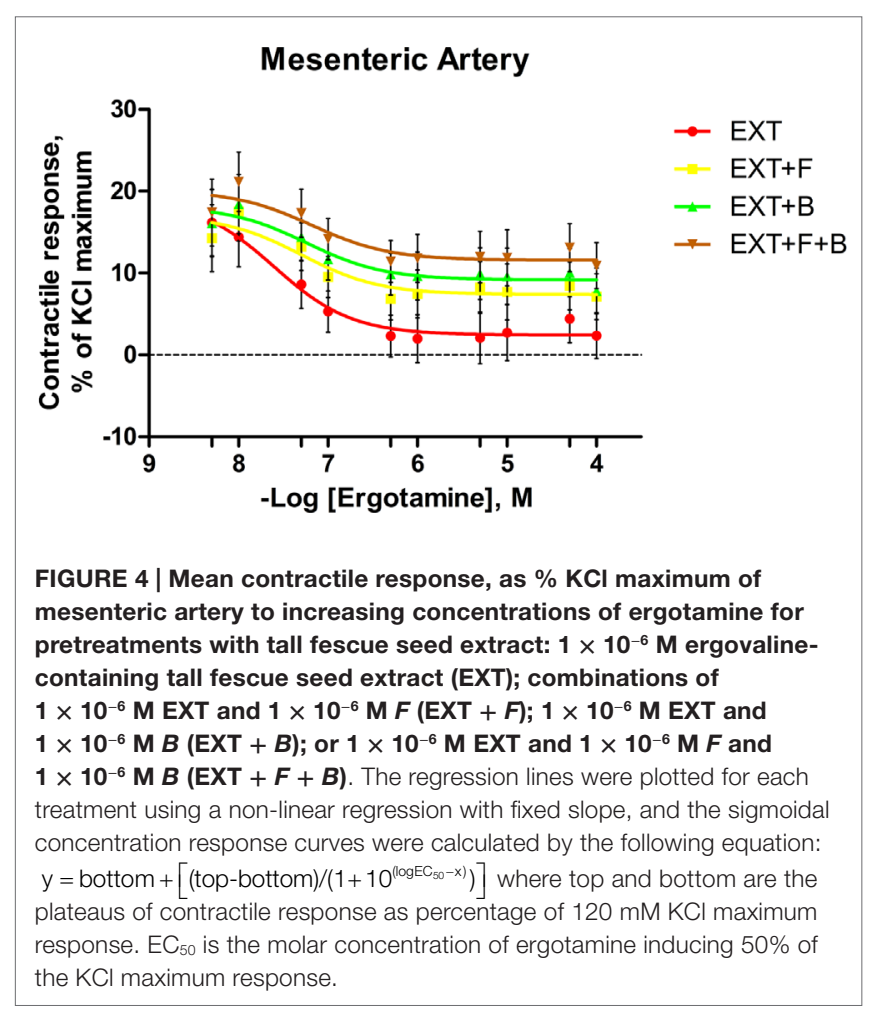

greater contractile responses to ERT at $1 \times 10^{-5}, 5 \times 10^{-5}$, and $1 \times 10^{-4} \mathrm{M}$ in mesenteric vein (main effect of $F$; $P<0.05$; Table 4). Within the $5 \times 10^{-5} \mathrm{M}$ ERT concentration, the contractile response of EXT was the lowest $(P=0.03)$. 


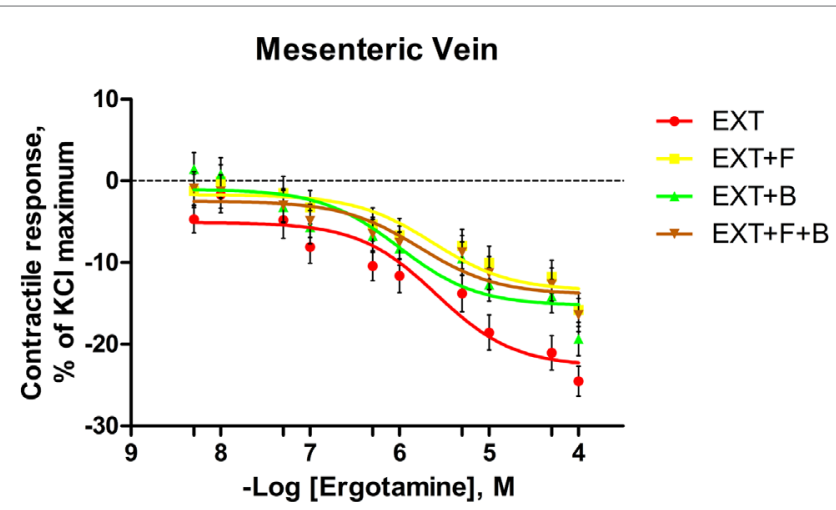

FIGURE 5 | Mean contractile response, as \% $\mathrm{KCl}$ maximum of mesenteric vein to increasing concentrations of ergotamine for pretreatments with tall fescue seed extract: $1 \times 10^{-6} \mathrm{M}$ ergovalinecontaining tall fescue seed extract (EXT); combinations of $1 \times 10^{-6} \mathrm{M}$ EXT and $1 \times 10^{-6} \mathrm{M} F(\mathrm{EXT}+F) ; 1 \times 10^{-6} \mathrm{M}$ EXT and $1 \times 10^{-6} \mathrm{M} B(\mathrm{EXT}+B)$; or $1 \times 10^{-6} \mathrm{M}$ EXT and $1 \times 10^{-6} \mathrm{M} F$ and $\mathbf{1} \times \mathbf{1 0}^{-6} \mathbf{M} \boldsymbol{B}(\mathbf{E X T}+\boldsymbol{F}+\boldsymbol{B})$. The regression lines were plotted for each treatment using a non-linear regression with fixed slope, and the sigmoidal concentration response curves were calculated by the following equation: $\mathrm{y}=$ bottom $+\left[(\right.$ top-bottom $\left.) /\left(1+10^{\left(\log _{\mathrm{EC}}-\mathrm{x}\right)}\right)\right]$ where top and bottom are the plateaus of contractile response as percentage of $120 \mathrm{mM} \mathrm{KCl}$ maximum response. $\mathrm{EC}_{50}$ is the molar concentration of ergotamine inducing $50 \%$ of the $\mathrm{KCl}$ maximum response.

\section{DISCUSSION}

This is the first study to investigate the interaction of ergot alkaloids and isoflavones on bovine mesenteric vasculature. Physiological effects of isoflavones and their metabolites on vasculature have been extensively studied on different vessel types in humans (24, 25 ) and rat models (26-29). The concentrations of isoflavones $\left(1 \times 10^{-6} \mathrm{M}\right.$ formononetin and biochanin $\left.\mathrm{A}\right)$ used in the current experiment were based on a study that reported dose-dependent formononetin- and biochanin A-induced relaxations of ratisolated thoracic aorta precontracted with phenylephrine (29). At $1 \times 10^{-6} \mathrm{M}$, formononetin and biochanin A were capable of inducing about 35 and $25 \%$ relaxation, respectively. Since the current study was the first to investigate interactions of isoflavones and ergot alkaloids, our rationale was to pick an intermediate concentration $\left(1 \times 10^{-6} \mathrm{M}\right)$ to avoid extreme scenarios and one that was equimolar with the concentration of ergovaline. The concentration of ergovaline-containing tall fescue seed extract that was chosen $\left(1 \times 10^{-6} \mathrm{M}\right)$ is based on the findings of Egert et al. (15), where $1 \times 10^{-6} \mathrm{M}$ of ergovaline-containing extract was observed to induce contractile response (about $40 \%$ of $\mathrm{KCl}$ maximum) of bovine mesenteric artery and vein.

Several studies have demonstrated that cattle grazing endophyte-infected tall fescue had reduced contractile responses to 5-hydroxytryptamine (5-HT) and as well as ergot alkaloids in the lateral saphenous vein $(16,17)$. Recently, a study using mesenteric artery and vein from steers that had been ruminally dosed with endophyte-infected tall fescue seed observed a decreased or completely absent constrictive response to ergot alkaloids (15). In the current study, an in vitro incubation of bovine mesenteric vasculature in a medium containing EXT was used to achieve an ergot
TABLE 4 | The analysis of variance and $P$-values of main effect of formononetin $(F)$, biochanin $A(B)$, and the interaction of formononetin and biochanin $A(F \times B)$ for pretreatments with tall fescue seed extract (EXT): $1 \times 10^{-6} \mathrm{M}$ (EXT); combinations of $1 \times 10^{-6} \mathrm{M}$ EXT and $F$, EXT and $B$, or $1 \times 10^{-6} M E X T+B+F$ on every ergotamine concentration.

\begin{tabular}{|c|c|c|c|}
\hline \multirow[t]{2}{*}{ Ergotamine concentration (M) } & \multicolumn{3}{|c|}{$P$-value } \\
\hline & $\boldsymbol{F}$ & $B$ & $F \times B$ \\
\hline \multicolumn{4}{|l|}{ Mesenteric artery } \\
\hline $5 \times 10^{-9}$ & 0.94 & 0.71 & 0.70 \\
\hline $1 \times 10^{-8}$ & 0.43 & 0.31 & 0.96 \\
\hline $5 \times 10^{-8}$ & 0.22 & 0.11 & 0.77 \\
\hline $1 \times 10^{-7}$ & 0.20 & 0.04 & 0.73 \\
\hline $5 \times 10^{-7}$ & 0.25 & 0.03 & 0.57 \\
\hline $1 \times 10^{-6}$ & 0.21 & 0.06 & 0.58 \\
\hline $5 \times 10^{-6}$ & 0.21 & 0.09 & 0.52 \\
\hline $1 \times 10^{-5}$ & 0.31 & 0.13 & 0.70 \\
\hline $5 \times 10^{-5}$ & 0.24 & 0.10 & 0.87 \\
\hline $1 \times 10^{-4}$ & 0.18 & 0.12 & 0.77 \\
\hline \multicolumn{4}{|l|}{ Mesenteric vein } \\
\hline $5 \times 10^{-9}$ & 0.75 & 0.07 & 0.10 \\
\hline $1 \times 10^{-8}$ & 0.91 & 0.77 & 0.41 \\
\hline $5 \times 10^{-8}$ & 0.45 & 0.98 & 0.50 \\
\hline $1 \times 10^{-7}$ & 0.18 & 0.85 & 0.32 \\
\hline $5 \times 10^{-7}$ & 0.15 & 0.48 & 0.19 \\
\hline $1 \times 10^{-6}$ & 0.19 & 0.58 & 0.32 \\
\hline $5 \times 10^{-6}$ & 0.16 & 0.44 & 0.27 \\
\hline $1 \times 10^{-5}$ & 0.03 & 0.30 & 0.12 \\
\hline $5 \times 10^{-5}$ & 0.02 & 0.17 & 0.08 \\
\hline $1 \times 10^{-4}$ & 0.01 & 0.24 & 0.14 \\
\hline
\end{tabular}

alkaloid pretreatment. The pretreatment of blood vessels with EXT (33) and isoflavones ( $F$ and $B$ ) were conducted at equimolar final concentrations of $1 \times 10^{-6} \mathrm{M}$. It has been reported that $F$ and $B$ both induced vasorelaxation in phenylephrine-precontracted rat-isolated thoracic aorta at $1 \times 10^{-6} \mathrm{M}$ (29). This latter study identified both nitric oxide from endothelial nitric oxide synthase (NOS) and potassium efflux from endothelial cells as putative mechanisms of action. However, the $1 \times 10^{-6} \mathrm{M}$ ergovaline in the EXT may be considered a high dose compared to the physiological levels encountered by cattle grazing endophyte-infected tall fescue (34). Nevertheless, the viability of mesenteric artery and vein was not compromised by concentration of ergot alkaloids used in the current study, as evidenced by the fact that both artery and vein were responsive to the final $\mathrm{KCl}$ addition.

Studies have reported that many isoflavones and their metabolites can reduce the vasoconstriction induced by $\mathrm{KCl}$ in several different vessel types using rat models $(28,35)$. The contractile response to $\mathrm{KCl}$ of endothelium-denuded rat aortic rings was inhibited by pretreatment with genistein or daidzein at both $3 \times 10^{-5}$ and $1 \times 10^{-4} \mathrm{M}$ for $30 \mathrm{~min}$ (36). However, in the same study, pretreatment with genistein or daidzein at $1 \times 10^{-5} \mathrm{M}$ did not relax the $\mathrm{KCl}$-induced vasoconstriction. The similar dose-dependent inhibition of $F\left(1 \times 10^{-5}, 3 \times 10^{-5}\right.$, and $1 \times 10^{-4} \mathrm{M}$ ) on the contractile response to $\mathrm{KCl}$ was observed in rat mesenteric arteries without endothelium (37), where $F$ again failed to inhibit $\mathrm{KCl}$-initiated contraction at $1 \times 10^{-5} \mathrm{M}$. However, in endothelium-intact rat aortic rings, Zhao et al. (38) reported that pretreatment with $1 \times 10^{-5}, 3 \times 10^{-5}$, and $5 \times 10^{-5} \mathrm{M}$ of $F$ all significantly inhibited the contractile response to $\mathrm{KCl}$ in a 
non-competitive manner. In the current study, the prior exposure to $F\left(1 \times 10^{-6} \mathrm{M}\right)$, biochanin $\mathrm{A}\left(1 \times 10^{-6} \mathrm{M}\right)$, and their combination did not have an impact on maximum contractile response of mesenteric artery and vein to $\mathrm{KCl}$ in treatments either with or without EXT. Since previous studies have indicated that the inhibition effects were dose-dependent $(36,37)$ and non-competitive (38), it is possible that the isoflavone concentration $\left(1 \times 10^{-6} \mathrm{M}\right)$ in the current study was not high enough to elicit any inhibitory effects on the $\mathrm{KCl}$ response. However, in the current study, maximum $\mathrm{KCl}$ responses were unaffected by $F$ and $B$, which validate the usage of $\mathrm{KCl}$ as a reference compound to normalize the contractile responses.

There is limited information about isoflavones' impact on blood vessel morphology in regards to vessel inside and outside diameters. In the current study, there was no significant evidence of an $F$ or $B$ effect on mesenteric artery inside or outside diameter regardless of EXT treatment. However, a tendency for a smaller inside diameter induced by $F$ treatment was observed in mesentery artery pretreated without EXT. One possible explanation for this could be the inhibitory effect of $F$ on vascular smooth muscle cells. Previously, estrogens [tamoxifen (39), estradiol (40)] and isoflavones $[F$ and $B(41)]$ have been shown to inhibit mitogeninduced proliferation, migration, and extracellular matrix synthesis of smooth muscle cells. On the other hand, the inside diameter of bovine lateral saphenous veins collected from steers grazing high-endophyte tall fescue pasture were smaller than those from steers grazing low-endophyte mixed-grass pasture (16). Likewise, Egert et al. (15) observed a smaller outside diameter of bovine mesenteric artery from endophyte-infected tall fescue seed-dosed steers than control steers. One possible explanation is the prolonged vasoconstriction induced by ergot alkaloids results in decreased inside or outside diameter. Additionally, the morphological changes of blood vessels, especially the expansion of the tunica media smooth muscle layer, could also lead to a smaller vessel insider diameter. It has been observed that calves given ethanolic extracts of tall fescue hay had symptoms of fescue foot and concomitant thickening of vessel walls and smaller vessel lumens in blood vessels of the coronary bands and tail tips (42). Similarly, Garner and Cornell (43) reported a thickening of the smooth muscle layer of peripheral blood vessels after consumption of endophyte-infected tall fescue. Although the exact mechanism associated with thickening of smooth muscle layer is unclear, evidence suggests hyperplasia over hypertrophy. Strickland et al. (44) reported that ergonovine, ergovaline, and $\alpha$-ergocryptine stimulate the growth and mitosis of quiescent bovine vascular smooth muscle cells in vitro. Although, in the present study, there was no significant impact of $F$ and $B$ pretreatment on mesenteric artery inside or outside diameters, the tendency of larger inside diameter caused by $F$ may indicate an alleviative effect on ergot alkaloids induced thickening of vessel walls and smaller lumens.

In the current study for pretreatments without EXT, ERT induced similar contractile response curves and $-\log ^{\mathrm{EC} 50}$ values (Control, $F, B$, and $F+B$ ) in mesenteric arteries. The shape of contractile responses were similar with Egert et al. (15), who reported ERT-induced contractile responses in mesenteric artery from steers, not exposed to ergot alkaloids, with a $-\log ^{\mathrm{EC} 50}$ value of $6.03 \pm 0.4 \mathrm{M}$. Whereas, the shape of mesenteric vein contractile response curves were in contrast to the observations of Egert et al. (15), which did not drop to negative values after reaching a maximum. Further, the maximum contractile response of mesenteric vein to ERT in the current study was also lower (10\% vs. $45 \%$ of $\mathrm{KCl}$ maximum). The blood vessels used in the previous study (15) did not undergo an in vitro pre-myograph incubation and utilized blood vessels from steers compared to heifers in the current study.

Substantial evidence has shown that many ergot alkaloids are vasoconstrictive in multiple types of vessels in various animal models $(7,8)$. Among these vasoactive ergot alkaloids, ERT and ergovaline were indicated as more potent vasoconstrictors with lower EC50 values (relative to other alkaloids) in bovine saphenous vein (45), ruminal vasculature (13), and mesenteric vasculature (15). The current observation of the contractile response induced by ERT was consistent with the previous findings in terms of vasoactivity for this alkaloid. Even though not completely defined yet, numerous studies have been conducted to investigate the mechanism of ergot alkaloid-caused vasoconstriction. The structural similarities of the ergoline ring system and several biogenic amines [i.e., (nor)epinephrine, serotonin, and dopamine] allows ergot alkaloids to interact with corresponding biogenic amine receptors as ligands $(30,46)$. Substantial evidence has shown that ergot alkaloids interact with dopamine-2 receptors $(47,48), \alpha_{1}$-adrenergic receptors $(49,50), \alpha_{2}$-adrenergic receptors (51), and $5-\mathrm{HT}_{2 \mathrm{~A}}$ receptors $(14,16,17)$. The binding with these $G$ protein-coupled receptors activates the subunit of the heterotrimeric $G$ protein and then triggers various secondary messaging systems and corresponding cytoplasmic signaling transductions. The vasoconstrictive response induced by ERT shown in the current study (Figure 2) could be explained by these agonistic mechanisms.

The pre-myograph incubation with EXT altered the contractile capacity of the mesenteric artery and vein. Using a bovine lateral saphenous vein model, Klotz et al. (16) found that 2,5-dimethoxy4-iodoamphetamine (DOI), a $5-\mathrm{HT}_{2 \mathrm{~A}}$ receptor agonist, induced vessel contractile intensities were $35 \%$ lower in high endophyteinfested tall fescue than in low-endophyte-infested tall fescue, whereas 5-carboxytryptamine (5- $\mathrm{HT}_{7}$ receptor agonist) produced greater $(37 \%)$ contractile intensities in high endophyte-infected tall fescue. Taken together, this indicated that chronic exposure to ergot alkaloids through grazing endophyte-infested tall fescue altered the vasoconstriction via serotonergic receptors. In a subsequent study, Klotz et al. (17) reported a suppression of the contractile response to ergovaline and 5-HT in steers grazing Kentucky-31 tall fescue infected with wild-type endophyte. Further, Egert et al. (15) demonstrated a similar reduced contractile response to ERT in mesenteric vasculature of steers treated with endophyte-infected tall fescue seed. Unsurprisingly, the antagonistic effects of ergot alkaloids to certain 5-HT receptors have been shown previously $(49,50,52)$. Collectively, it is possible that the EXT pretreatment in the present experiment reduced the vasoconstriction to ERT via altering the biogenic amine receptor activities.

Many in vitro bioassays have demonstrated that, in various vessel types and in numerous species, the binding of ergovaline and receptor was irreversible, or the dissociation from the receptor was very slow $(14,45,50,53)$. Likewise, an apparent bioaccumulation 
was reported in bovine lateral saphenous veins after repetitive exposures of ergovaline in vitro (54). Additionally, studies have indicated that ergot alkaloid-induced constriction is prolonged and wash-resistant in human superficial temporal artery (55) and coronary artery (56). These findings may explain the high contractile response to the initial ERT addition $\left(5 \times 10^{-9} \mathrm{M}\right)$ in mesenteric arteries that were pretreated with EXT $\left(1 \times 10^{-6} \mathrm{M}\right.$ ergovaline) in the current study. Furthermore, using an inositol phosphate accumulation assay, Unett et al. (57) reported that as a $5-\mathrm{HT}_{2 \mathrm{~B}}$ agonist, ERT maintained similar potencies after 2 or 4-h extensive washout and this was due to internalization or sequestration of the active ERT-bound receptor. It has been demonstrated that ERT and ergovaline are equally potent vasoconstrictors inducing similar contractile responses (45). Thus, these findings support the observations in the current study that the elevated contractile response to very low concentrations of ERT pretreated with EXT was numerically similar to $1 \times 10^{-6} \mathrm{M}$ ERT-induced contractile response of mesenteric artery without EXT incubation. This can be attributed to prior exposure to ergovaline (in EXT) leading up to the myograph portion of the experiment, and possible carry over of the vascular response to ergovaline to the dose response to ERT.

In the present study, prior exposure to $F$ and $B$ failed to consistently alter the mesenteric vasculature contraction induced by ERT. As discussed earlier in this section, numerous studies have shown the vasodilative effect of isoflavones and their metabolites in different vessel types. Pretreatment with $F\left(3 \times 10^{-5}\right.$ and $5 \times 10^{-5} \mathrm{M}$ ) antagonized contractile responses of rat thoracic aortas to norepinephrine in a non-competitive manner (38). Sun et al. (37) hypothesized that pre-incubation with $F\left(3 \times 10^{-5}\right.$ and $1 \times 10^{-4} \mathrm{M}$ ) depressed the contraction of rat mesenteric artery to phenylephrine and 5-HT, and similarly, depression was not observed when $F$ at $1 \times 10^{-5} \mathrm{M}$. The $1 \times 10^{-6} \mathrm{M} F$ and $B$ concentrations in the present study were possibly not high enough to elicit sufficient vasorelaxation to offset the ERT-induced vasoconstriction. Other evidence of the chronic antihypertensive effect of $F$ has been reported based on male spontaneously hypertensive rats (SHR) (58). They found that the vasoconstriction of mesenteric artery segments induced by phenylephrine or 5-HT was reduced in $F(50 \mathrm{mg} / \mathrm{kg}$ per day) orally administrated to SHR. The expression of $\alpha_{1}$-adrenoceptors and $5-\mathrm{HT}_{2 \mathrm{~A} / 1 \mathrm{~B}}$ receptors in mesenteric artery of $F$ treated SHR decreased (58).

Even though there might be some species differences between bovine and SHR, the 2-h pre-myograph incubation with $F$ or $B$ in the present study may not be long enough to permit expression or induction of NOS by the tissues that were used. However, sodium- and ATP-dependent $\mathrm{K}+$ transport mechanisms, like those described by $\mathrm{Wu}$ et al. (29), are very rapid. Further, F

\section{REFERENCES}

1. Bacon CW, Porter JK, Robbins JD, Luttrell ES. Epichloë typhina from toxic tall fescue grasses. Appl Environ Microbiol (1977) 34:576-81.

2. Porter JK, Bacon CW, Robbins JD. Ergosine, ergosinine, and chanoclavine I from Epichloë typhina. J Agric Food Chem (1979) 27:595-8. doi:10.1021/ jf60223a045

3. Bush LP, Cornelius PL, Buckner RC, Varney DR, Chapman RA, Burrus $\mathrm{PB}$, et al. Association of $\mathrm{N}$-acetyl loline and $\mathrm{N}$-formyl loline with and $B$ are metabolized to daidzein and genistein in the rumen (59). As many metabolic studies have found, daidzein is further metabolized by rumen and intestinal bacteria to equol, which has a higher estrogenic potency than its isoflavone precursor $(22,23$, 59). Equol undergoes renal clearance by clover-fed ruminants $(60,61)$, which indicates that equol, rather than formononetin, is present in the blood. It is possible that equol and other bacterial metabolites of isoflavones could have greater effects on bovine blood vessels. Thus, the different routes of administration of isoflavone treatments (in vivo vs. in vitro) may account some of the inconsistencies, and the idea that bacterial or animal metabolism might influence vasorelaxation is consistent with the aforementioned results by Sun et al. (58).

With EXT in the pretreatment media, $F$ and $B$ increased the contractile response of mesenteric artery at several ERT concentrations. This has provided the first evidence that the isoflavones, $F$ and $B$, have potential to alleviate the vasoconstrictive effect of ergot alkaloids. However, based on the current knowledge from ergot alkaloids and isoflavones, there is little to mechanistically explain this phenomenon, so more investigations on their interactions are needed.

\section{CONCLUSION}

In conclusion, this study indicated that a pre-myograph incubation with $F, B$ at $1 \times 10^{-6} \mathrm{M}$ and their combination did not affect the contractile response to ERT in mesenteric vasculature. The pre-myograph incubation of mesenteric vasculature with EXT (equivalent to $1 \times 10^{-6} \mathrm{M}$ ergovaline) reduced the vasoactivity of ERT, and there were some indications that $F$ and $B$ may alleviate this reduction. At higher concentrations, $F$ and $B$ may alleviate this reduction in vasoactivity caused by prior exposure to ergot alkaloids. Future studies with higher isoflavone dosages or longer exposure may be helpful to further investigate the ergot alkaloids and isoflavones interaction. Additionally, this study was confined to the mesenteric veins and arteries. It is plausible that effects could be elicited in other vessels with different expression levels of 5-HT, NOS, or other factors. In vivo research, which takes isoflavone metabolism into account, is necessary to better understand the interaction from a practical perspective.

\section{ACKNOWLEDGMENTS}

The authors sincerely acknowledge Adam J. Barnes of USDAARS, Forage-Animal Production Research Unit; Kirk Vanzant and Lauren Clark of the University of Kentucky Beef Unit; Ryan Chaplin of the University of Kentucky Meats Lab for the great efforts they contributed on this study.

Epichloë-typhina in tall fescue. Crop Sci (1982) 22:941-3. doi:10.2135/ cropsci1982.0011183X002200050010x

4. Leuchtmann A, Bacon CW, Schardl CL, White JF, Tadych M. Nomenclatural realignment of Neotyphodium species with genus Epichloë. Mycologia (2014) 106:202-15. doi:10.3852/13-251

5. Lyons PC, Plattner RD, Bacon CW. Occurrence of peptide and clavine ergot alkaloids in tall fescue grass. Science (1986) 232:487-9. doi:10.1126/science.3008328

6. Yates SG, Powell RG. Analysis of ergopeptine alkaloids in endophyte-infected tall fescue. J Agric Food Chem (1988) 36:337-40. doi:10.1021/jf00080a023 
7. Strickland JR, Aiken GE, Klotz JL. Ergot alkaloid induced blood vessel dysfunction contributes to fescue toxicosis. Forage Grazinglands (2009) 7. doi:10.1094/FG-2009-1104-01-RS

8. Strickland JR, Looper ML, Matthews JC, Rosenkrans CF Jr, Flythe MD, Brown KR. Board-invited review: St. Anthony's Fire in livestock: causes, mechanisms, and potential solutions. J Anim Sci (2011) 89:1603-26. doi:10.2527/ jas.2010-3478

9. Aiken GE, Kirch BH, Strickland JR, Bush LP, Looper ML, Schrick FN. Hemodynamic responses of the caudal artery to toxic tall fescue in beef heifers. J Anim Sci (2007) 85:2337-45. doi:10.2527/jas.2006-821

10. Aiken GE, Strickland JR, Looper ML, Bush LP, Schrick FN. Hemodynamics are altered in the caudal artery of beef heifers fed different ergot alkaloid concentrations. J Anim Sci (2009) 87:2142-50. doi:10.2527/jas.2008-1562

11. Solomons RN, Oliver JW, Linnabary RD. Reactivity of dorsal pedal vein of cattle to selected alkaloids associated with Acremonium coenophialum-infected fescue grass. Am J Vet Res (1989) 50:235-8.

12. Klotz JL, Bush LP, Smith DL, Shafer WD, Smith LL, Vevoda AC, et al. Assessment of vasoconstrictive potential of D-lysergic acid using an isolated bovine lateral saphenous vein bioassay. J Anim Sci (2006) 84:3167-75. doi:10.2527/jas.2006-038

13. Foote AP, Harmon DL, Strickland JR, Bush LP, Klotz JL. Effect of ergot alkaloids on contractility of bovine right ruminal artery and vein. J Anim Sci (2011) 89:2944-9. doi:10.2527/jas.2010-3626

14. Dyer DC. Evidence that ergovaline acts on serotonin receptors. Life Sci (1993) 53:L223-8. doi:10.1016/0024-3205(93)90555-H

15. Egert AM, Kim DH, Schrick FN, Harmon DL, Klotz JL. Dietary exposure to ergot alkaloids decreases contractility of bovine mesenteric vasculature. $J$ Anim Sci (2014) 92:1768-79. doi:10.2527/jas.2013-7141

16. Klotz JL, Brown KR, Xue Y, Matthews JC, Boling JA, Burris WR, et al. Alterations in serotonin receptor-induced contractility of bovine lateral saphenous vein in cattle grazing endophyte-infected tall fescue. J Anim Sci (2012) 90:682-93. doi:10.2527/jas.2011-4323

17. Klotz JL, Aiken GE, Johnson JM, Brown KR, Bush LP, Strickland JR. Antagonism of lateral saphenous vein serotonin receptors from steers grazing endophyte-free, wild-type, or novel endophyte-infected tall fescue. J Anim Sci (2013) 91:4492-500. doi:10.2527/jas.2012-5896

18. Price KR, Fenwick GR. Naturally occurring oestrogens in foods - a review. Food Addit Contam (1985) 2:73-106. doi:10.1080/02652038509373531

19. Franke AA, Custer LJ, Cerna CM, Narala KK. Quantitation of phytoestrogens in legumes by HPLC. J Agric Food Chem (1994) 42:1905-13. doi:10.1021/ Jf00045a015

20. Anderson JJ, Garner SC. Phytoestrogens and human function. Nutr Today (1997) 32:232-9. doi:10.1097/00017285-199711000-00003

21. Kurzer MS, Xu X. Dietary phytoestrogens. Annu Rev Nutr (1997) 17:353-81. doi:10.1146/annurev.nutr.17.1.353

22. Dixon RA. Phytoestrogens. Annu Rev Plant Biol (2004) 55:225-61. doi:10.1146/ annurev.arplant.55.031903.141729

23. Beck V, Rohr U, Jungbauer A. Phytoestrogens derived from red clover: an alternative to estrogen replacement therapy? J Steroid Biochem Mol Biol (2005) 94:499-518. doi:10.1016/j.jsbmb.2004.12.038

24. Walker HA, Dean TS, Sanders TA, Jackson G, Ritter JM, Chowienczyk PJ. The phytoestrogen genistein produces acute nitric oxide-dependent dilation of human forearm vasculature with similar potency to 17beta-estradiol. Circulation (2001) 103:258-62. doi:10.1161/01.CIR.103.2.258

25. Chin-Dusting JP, Boak L, Husband A, Nestel PJ. The isoflavone metabolite dehydroequol produces vasodilatation in human resistance arteries via a nitric oxide-dependent mechanism. Atherosclerosis (2004) 176:45-8. doi:10.1016/j. atherosclerosis.2004.03.025

26. Gimenez I, Lou M, Vargas F, Alvarez-Guerra M, Mayoral JA, Martinez RM, et al. Renal and vascular actions of equol in the rat. J Hypertens (1997) 15:1303-8. doi:10.1097/00004872-199715110-00015

27. Chin-Dusting JP, Fisher LJ, Lewis TV, Piekarska A, Nestel PJ, Husband A. The vascular activity of some isoflavone metabolites: implications for a cardioprotective role. Br J Pharmacol (2001) 133:595-605. doi:10.1038/sj.bjp.0704088

28. Jackman KA, Woodman OL, Chrissobolis S, Sobey CG. Vasorelaxant and antioxidant activity of the isoflavone metabolite equol in carotid and cerebral arteries. Brain Res (2007) 1141:99-107. doi:10.1016/j.brainres.2007.01.007

29. Wu JH, Li Q, Wu MY, Guo DJ, Chen HL, Chen SL, et al. Formononetin, an isoflavone, relaxes rat isolated aorta through endothelium-dependent and endothelium-independent pathways. J Nutr Biochem (2010) 21:613-20. doi:10.1016/j.jnutbio.2009.03.010

30. Berde B. Ergot compounds: a synopsis. Adv Biochem Psychopharmacol (1980) 23:3-23.

31. Nevala R, Korpela R, Vapaatalo H. Plant derived estrogens relax rat mesenteric artery in vitro. Life Sci (1998) 63:L95-100. doi:10.1016/S0024-3205(98)00300-2

32. Klotz JL, Barnes AJ. Isolating and using sections of bovine mesenteric artery and vein as a bioassay to test for vasoactivity in the small intestine. J Vis Exp (2014) 92:e52020. doi:10.3791/52020

33. Foote AP, Harmon DL, Brown KR, Strickland JR, Mcleod KR, Bush LP, et al. Constriction of bovine vasculature caused by endophyte-infected tall fescue seed extract is similar to pure ergovaline. J Anim Sci (2012) 90:1603-9. doi:10.2527/jas.2011-4513

34. Craig AM, Klotz JL, Duringer JM. Cases of ergotism in livestock and associated ergot alkaloid concentrations in feed. Front Chem (2015) 3:8. doi:10.3389/ fchem.2015.00008

35. Jiang C, Sarrel PM, Lindsay DC, Poole-Wilson PA, Collins P. Endotheliumindependent relaxation of rabbit coronary artery by $17 \beta$-oestradiol in vitro. Br J Pharmacol (1991) 104:1033-7. doi:10.1111/j.1476-5381.1991.tb12545.x

36. Seok YM, Baek I, Kim YH, Jeong YS, Lee IJ, Shin DH, et al. Isoflavone attenuates vascular contraction through inhibition of the RhoA/Rho-kinase signaling pathway. J Pharmacol Exp Ther (2008) 326:991-8. doi:10.1124/ jpet.108.138529

37. Sun T, Liu R, Cao YX. Vasorelaxant and antihypertensive effects of formononetin through endothelium-dependent and -independent mechanisms. Acta Pharmacol Sin (2011) 32:1009-18. doi:10.1038/aps.2011.51

38. Zhao Y, Chen B-N, Wang S-B, Wang S-H, Du G-H. Vasorelaxant effect of formononetin in the rat thoracic aorta and its mechanisms. J Asian Nat Prod Res (2012) 14:46-54. doi:10.1080/10286020.2011.628939

39. Grainger DJ, Metcalfe JC. Tamoxifen: teaching an old drug new tricks? Nat Med (1996) 2:381-5. doi:10.1038/nm0496-381

40. Rosselli M, Keller P, Kern F, Hahn A, Dubey R. Estradiol inhibits mitogen-induced proliferation and migration of human aortic smooth-muscle cells-implications for cardiovascular-disease in women. Circulation (1994) 90: 87.

41. Dubey RK, Gillespie DG, Imthurn B, Rosselli M, Jackson EK, Keller PJ. Phytoestrogens inhibit growth and MAP kinase activity in human aortic smooth muscle cells. Hypertension (1999) 33:177-82. doi:10.1161/01.HYP.33.1.177

42. Williams M, Shaffer SR, Garner GB, Yates SG, Tookey HL, Kintner LD, et al. Induction of fescue foot syndrome in cattle by fractionated extracts of toxic fescue hay. Am J Vet Res (1975) 36:1353-7.

43. Garner G, Cornell C. Fescue foot in cattle. In: Wyllie TD, Morehouse LG, editors. Mycotoxic Fungi, Mycotoxins, Mycotoxicoses: An Encyclopedic Handbook. (Vol. 2), New York: Marcel Dekker (1978). p. 45-62.

44. Strickland J, Bailey E, Abney L, Oliver J. Assessment of the mitogenic potential of the alkaloids produced by endophyte (Acremonium coenophialum)-infected tall fescue (Festuca arundinacea) on bovine vascular smooth muscle in vitro. J Anim Sci (1996) 74:1664-71.

45. Klotz JL, Bush LP, Smith DL, Shafer WD, Smith LL, Arrington BC, et al. Ergovaline-induced vasoconstriction in an isolated bovine lateral saphenous vein bioassay. J Anim Sci (2007) 85:2330-6. doi:10.2527/jas.2006-803

46. Weber HP. The molecular architecture of ergopeptines: a basis for biological interaction. Adv Biochem Psychopharmacol (1980) 23:25-34.

47. Larson BT, Sullivan DM, Samford MD, Kerley MS, Paterson JA, Turner JT. D2 dopamine receptor response to endophyte-infected tall fescue and an antagonist in the rat. J Anim Sci (1994) 72:2905-10.

48. Larson BT, Samford MD, Camden JM, Piper EL, Kerley MS, Paterson JA, et al. Ergovaline binding and activation of D2 dopamine receptors in GH4ZR7 cells. J Anim Sci (1995) 73:1396-400.

49. Oliver JW, Abney LK, Strickland JR, Linnabary RD. Vasoconstriction in bovine vasculature induced by the tall fescue alkaloid lysergamide. J Anim Sci (1993) 71:2708-13.

50. Schoning C, Flieger M, Pertz HH. Complex interaction of ergovaline with 5-HT2A, 5-HT1B/1D, and alphal receptors in isolated arteries of rat and guinea pig. J Anim Sci (2001) 79:2202-9. doi:2001.7982202x

51. Oliver JW, Strickland JR, Waller JC, Fribourg HA, Linnabary RD, Abney LK. Endophytic fungal toxin effect on adrenergic receptors in lateral saphenous veins (cranial branch) of cattle grazing tall fescue. JAnim Sci (1998) 76:2853-6.

52. Pertz H, Eich E. Ergot alkaloids and their derivatives as ligands for serotoninergic, dopaminergic, and adrenergic receptors. In: Vladimir K, Ladislave 
C, editors. Ergot: The Genus Claviceps. Amsterdam: Harwood Academic Publishers (1999). $411 \mathrm{p}$.

53. Pesqueira A, Harmon D, Branco A, Klotz J. Bovine lateral saphenous veins exposed to ergopeptine alkaloids do not relax. J Anim Sci (2014) 92:1213-8. doi:10.2527/jas.2013-7142

54. Klotz JL, Kirch BH, Aiken GE, Bush LP, Strickland JR. Bioaccumulation of ergovaline in bovine lateral saphenous veins in vitro. J Anim Sci (2009) 87:2437-47. doi:10.2527/jas.2008-1692

55. Ostergaard JR, Mikkelsen E, Voldby B. Effects of 5-hydroxytryptamine and ergotamine on human superficial temporal artery. Cephalalgia (1981) 1:223-8. doi:10.1046/j.1468-2982.1981.0104223.x

56. Vandenbrink AM, Reekers M, Bax WA, Ferrari MD, Saxena PR. Coronary side-effect potential of current and prospective antimigraine drugs. Circulation (1998) 98:25-30. doi:10.1161/01.CIR.98.1.25

57. Unett DJ, Gatlin J, Anthony TL, Buzard DJ, Chang S, Chen C, et al. Kinetics of 5-HT2B receptor signaling: profound agonist-dependent effects on signaling onset and duration. J Pharmacol Exp Ther (2013) 347:645-59. doi:10.1124/ jpet.113.207670

58. Sun T, Wang J, Huang LH, Cao YX. Antihypertensive effect of formononetin through regulating the expressions of eNOS, 5-HT2A/1B receptors and alpha1-adrenoceptors in spontaneously rat arteries. Eur J Pharmacol (2013) 699:241-9. doi:10.1016/j.ejphar.2012.10.031
59. Dickinson JM, Smith GR, Randel RD, Pemberton IJ. In vitro metabolism of formononetin and biochanin A in bovine rumen fluid. J Anim Sci (1988) 66:1969-73.

60. Nottle MC, Beck AB. Urinary sediments in sheep feeding on estrogenic clover. 3. Identification of 4'-O-methyl-equol as a major component of some sediments. Aust J Agric Res (1974) 25:509-14. doi:10.1071/ Ar9740509

61. Njastad KM, Adler SA, Hansen-Moller J, Thuen E, Gustavsson AM, Steinshamn H. Gastrointestinal metabolism of phytoestrogens in lactating dairy cows fed silages with different botanical composition. J Dairy Sci (2014) 97:7735-50. doi:10.3168/jds.2014-8208

Conflict of Interest Statement: The authors declare that the research was conducted in the absence of any commercial or financial relationships that could be construed as a potential conflict of interest.

Copyright $\odot 2015 \mathrm{Jia}$, Harmon, Flythe and Klotz. This is an open-access article distributed under the terms of the Creative Commons Attribution License (CC BY). The use, distribution or reproduction in other forums is permitted, provided the original author(s) or licensor are credited and that the original publication in this journal is cited, in accordance with accepted academic practice. No use, distribution or reproduction is permitted which does not comply with these terms. 